\title{
TRAPICHE RUBIES
}

\author{
By Karl Schmetzer, Henry A. Hänni, Heinz-Jürgen Bernhardt, and \\ Dietmar Schwar'
}

Ruby crystals from Southeast Asia with a fixed six-rayed star, similar in effect to trapiche emeralds from Colombia, are described. They consist of six transparent-to-translucent ruby sectors separated by nontransparent yellow or white planes. Most samples also have a hexagonal tapered yellow, black, or red core. In the yellow or white arms of the star and in the boundary zones between the core and the six ruby sectors, a massive concentration of tube-like inclusions is seen. These inclusions are oriented perpendicular to the morphologically dominant dipyramidal crystal faces; they contain liquid, two-phase (liquid/gas), and solid fillings identified as magnesium-bearing calcite and dolomite. A trapiche-type sapphire is also described.

\section{ABOUT THE AUTHORS}

Dr. Schmetzer is a research scientist residing in Petershausen, near Munich, Germany. Dr. Hänni is director of SSEF Swiss Gemmological institute, Basel, and professor of gemology at Basel University, Switzerland. Dr. Bernhardt is a research scientist at the Institute for Mineralogy of RuhrUniversity, Bochum, Germany. Dr. Schwarz is head of research at the Gubelin Gemmological Laboratory, Luceme, Switzerland. All photos and photomicrographs are by the authors unless otherwise noted.

Acknowledgments: The authors are grateful to Dr. O. Medenbach of Bochum University for photomicrography of the polished sections and X-ray powder diffraction analysis.

Gems \& Gemology, Vol. 32, No. 4, pp. 242-250.

(C) 1996 Gemological institute of America
1 n October 1995, a 6.0 ct cabochon-cut ruby with a distinct sectored appearance-similar to that associated with trapiche emeralds-was shown to one of the authors (KS) by a gem collector who resides near Munich, Germany. This sample was first described by Müllenmeister and Zang (1995) and also briefly mentioned by Henn and Bank (1996). The unusual cabochon consists of six transparent ruby sectors delineated by six nontransparent (i.e., translucent-to-opaque) yellow arms in the form of a fixed six-rayed star. Myanmar was mentioned as country of origin by the Idar-Oberstein gem dealer who originally sold the stone (R. Goerlitz, pers. comm., 1996). Scanning electron microscope (SEM) examination of this sample revealed the presence of what are most probably carbonates-mainly calcite plus some subordinate ankerite-in the arms of the star (Müllenmeister and Zang, 1995), and carbonates were also mentioned by Henn and Bank (1996). SEM-EDS (energy-dispersive spectroscopy) revealed the characteristic peaks of $\mathrm{Ca}, \mathrm{Mg}, \mathrm{Fe}$, and C (U. Henn, pers. comm., 1996).

In November 1995, subsequent to the 25th International Gemmological Conference in Thailand, three of the authors (KS, HAH, and DS) visited the ruby market of Mae Sai, close to the Myanmar border, where great quantities of rough and some fashioned rubies were offered for sale. The dealers said that the material on display originated from the Mong Hsu mining area in Myanmar (see Peretti et al., 1995). After two days of searching, we obtained one cabochon (figure 1) and about 30 rough samples of sectored ruby similar to the piece seen in Germany. Some days later, one of the authors (DS) acquired more than 70 additional rough sectored crystals from various dealers in Bangkok. For these samples, the suppliers mentioned Vietnam and Myanmar as possible countries of origin. In total, more than 100 trapiche-type rubies were available for the present study. In the course of our research, we also encountered one gray trapiche-type sapphire (Box A).

\section{MATERIALS AND METHODS}

All samples were examined macroscopically as well as by conventional microscopic techniques in reflected and transmitted light. Eighteen samples, which represented all of the structural varieties seen, were sawn into three or four slices each. 
The slices were oriented three ways: (1) parallel to the c-axis and parallel to one of the arms of the sixrayed stars, (2) parallel to the c-axis and perpendicular to one of the arms of the stars, or (3) perpendicular to the c-axis. From these slices, we had polished slabs about $1.0-1.3 \mathrm{~mm}$ thick prepared for each of the 18 crystals, as well as 10 polished sections about $200 \mu \mathrm{m}$ thick and two approximately $20 \mu \mathrm{m}$ polished thin sections. We cut an additional 30 pieces of rough in one direction and polished one side to view the internal structure.

We examined the polished slabs with a gemological microscope, first with fiber-optic illumination and then immersed in methylene iodide. The polished sections were examined with conventional petrographic microscopes (Leitz and Zeiss).

To identify the solid inclusions, we used two microanalytical techniques: 10 of the polished slabs were examined by Raman spectroscopy with a Renishaw Raman microscope (see Hänni et al., 1996, for experimental details), and eight of the approximately $200 \mu \mathrm{m}$ thick polished sections were analyzed with a CAMECA Camebax SX 50 electron microprobe.

For additional chemical characterization of the material forming the arms of the six-rayed stars and comparison with the chemistry of the host ruby, we submitted five natural crystal fragments and six polished slabs to energy-dispersive X-ray fluorescence (EDXRF) analysis using a Philips PV $9500 \mathrm{X}$-ray generator and detectors with a Spectrace TX-6100 system and software package. We used lead foils with specially prepared holes to restrict analysis to the ruby areas only (without any arm component) and to analyze areas that included part of a yellow arm and some adjacent ruby.

In addition, yellow, nontransparent (translucent-to-opaque), triangular areas with massive inclusions in the outer zones of two samples were examined both by electron microprobe and by Xray diffraction analysis (using a conventional 57.3 $\mathrm{mm}$ diameter Gandolfi camera).

\section{VISUAL APPEARANCE}

We first examined the samples with the unaided eye or a $10 \times$ loupe. All of the rough samples were fragments of barrel-shaped crystals; they ranged from about 3 to $8 \mathrm{~mm}$ in diameter and from 3 to 10 $\mathrm{mm}$ in length. Some were water-worn, but others revealed a distinct striated surface structure on planes more or less parallel to the basal pinacoid (figure 2). About 20 of the crystal fragments had natural faces, all with a uniform habit consisting of

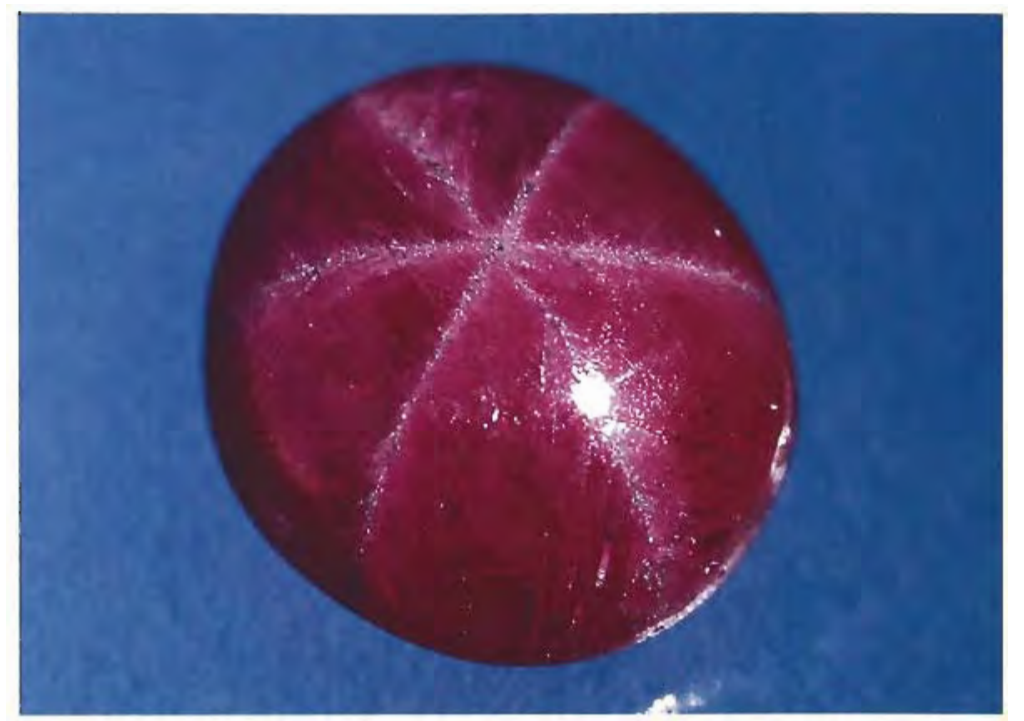

Figure 1. Trapiche-type rubies have been seen in Southeast Asian gem markets. This $1.55 \mathrm{ct}$ cabochon was purchased in Mae Sai, Thailand, from among material that was mined in Mong Hsu, Myanmar. As is the case with trapiche emeralds, the six-rayed star is fixed; that is, it does not move when the stone or light source is moved.

a single dipyramidal crystal form. These faces were inclined about $5^{\circ}$ to the c-axis, which indicates that the dominant form is the hexagonal dipyramid $\omega$ $\left\{\begin{array}{llll}14 & 14 & 28 & 3\end{array}\right\}$. Three crystals had one or two additional rhombohedral faces $r(10 \overline{1} 1)$.

The divided structure of the crystals was best seen in those polished slabs oriented perpendicular to the c-axis. In these hexagonal crosssections, six red, transparent-to-translucent sectors were subdivided by the yellow- or whiteappearing arms of a six-rayed star. In some crystals, the six arms (which, unlike typical asteriated gems, are fixed-that is, they do not move when the stone or light source is moved) intersected at one small point, forming six triangular ruby sectors (figure 3). In many cases, however, the arms extended outward from a hexagonal central core (figure 4), producing trapezoidal ruby areas. The cores of our study samples were usually either opaque yellow or black (figure 5); in some cases, they were transparent red. We also saw thin yellow or (rarely) white zones, similar in color to the arms of the stars, in the boundaries between the black or red cores and the six triangular ruby sectors (see, e.g., figures 4 and 5).

In some samples, only a small intersection point between the six yellow arms of the star was 


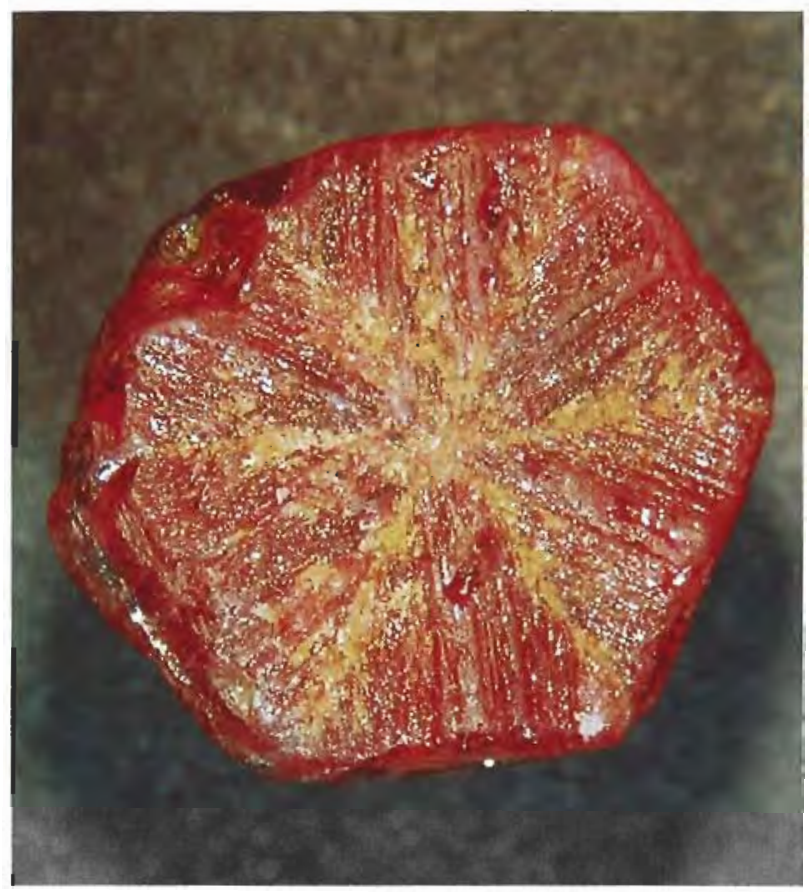

Figure 2. The six-rayed (hexagonal) star in this 7.5mm-diameter trapiche ruby separates the ruby into six triangular sectors. Note the surface striations oriented perpendicular to the six dipyramidal faces of this crystal, almost parallel to the basal pinacoid.

observed on both sides of a crystal fragment or polished slab. In most cases, however, distinct cores were seen, revealing a pyramidal or tapered outline (figure 6). That is, the diameters of the red, yellow, or black cores varied between the two ends of the crystal fragments or between the two sides of the polished slabs (figures 3 and 5). In most cases, the cores or intersection points at both ends were the same color; however, we also saw a few barrelshaped samples with different colors at either end.

In some samples, yellow, nontransparent, feathery structures extended outward from the dividing planes into the transparent ruby sectors, forming triangular areas of massive inclusions toward the edges of the crystals (figure 7). Occasionally, these zones had been weathered out (figure 8).

\section{MICROSCOPIC EXAMINATION}

In transmitted light, the yellow or black central cores, the six yellow arms of the stars, and the yellow triangular areas appeared opaque (figure 9). We observed a series of parallel tube-like structures or striations extending outward from the cores or arms into the ruby sectors (figure 10). Where the ruby sectors were transparent, these structures were largely restricted to thin areas close to the central core and the arms (figure 11), although some tubes did run through the full transparent

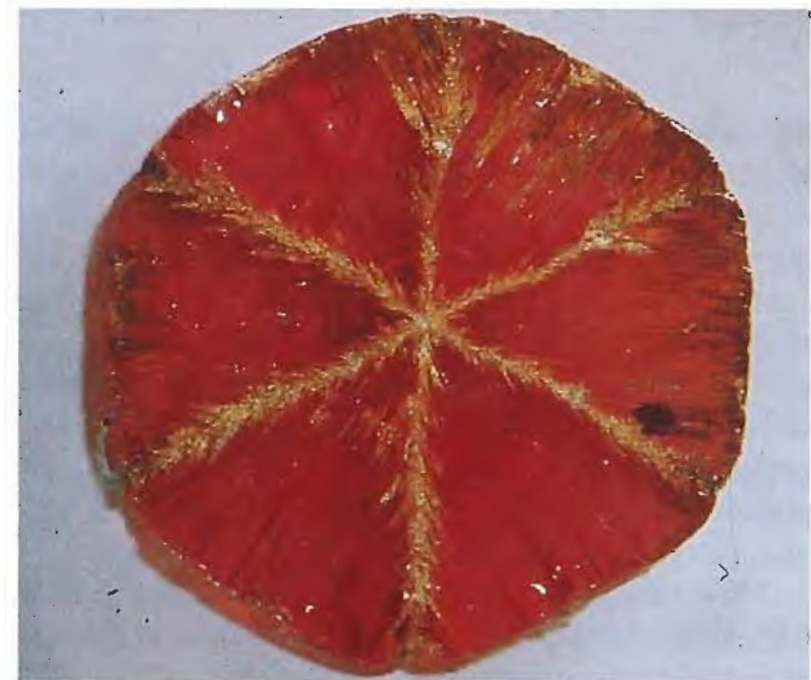

Figure 3. In some of the trapiche rubies, the six arms intersect at one small point, forming six triangular ruby sectors. This polished slab is about 4.2 $\mathrm{mm}$ in diameter.

sectors to the outer dipyramidal faces of the crystal. Those ruby sectors that were semi-transparent to translucent had more of the tube-like inclusions.

Examination of the polished sections revealed the same characteristic patterns noted above, with striations restricted to the arms and boundaries between the cores and transparent ruby sectors (figure $12 \mathrm{a}, \mathrm{b}, \mathrm{c}$ ) and a dense concentration of tubes in semi-transparent samples (figure $12 \mathrm{e}, \mathrm{f}$ ). In some samples, the six arms intersected in a small point, that is, without a core (figure 12a, e); others had a small transparent red (figure 12f), a small nontrans-

Figure 4. In many of the trapiche rubies, the arms radiate from a hexagonal central core, so the six nuby sectors are trapezoidal. This polished slab measures about $3.2 \mathrm{~mm}$ in diameter.

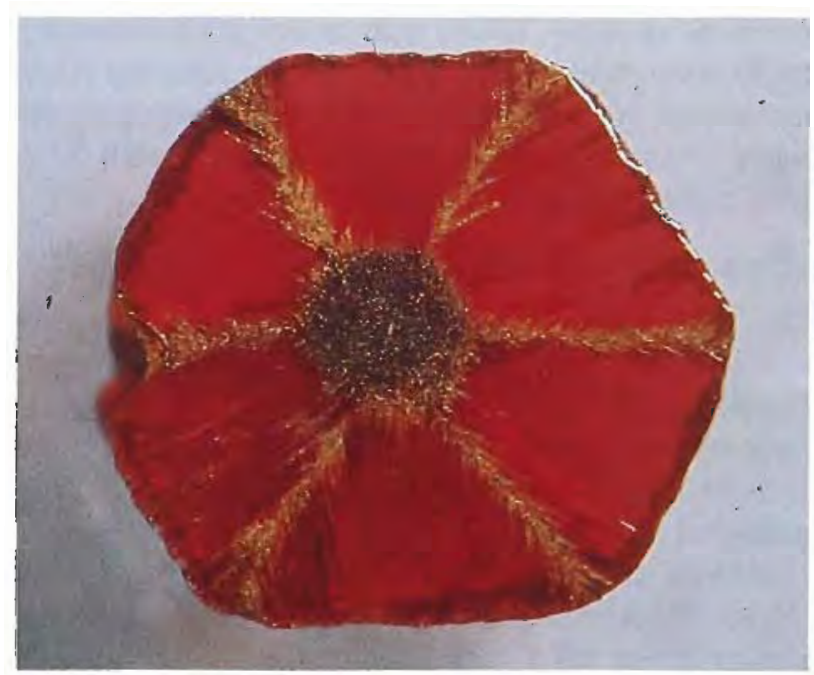




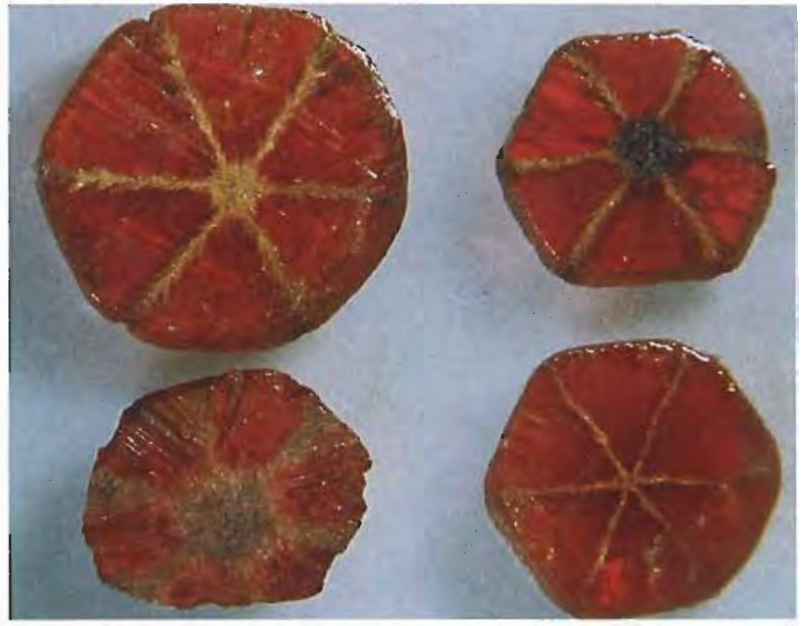

Figure 5. These trapiche ruby cross-sections illustrate some of the different forms observed in the samples examined. The arms of the stars intersect in a small point (lower right) or extend outward from the corners of a hexagonal black (upper right and lower left) or yellow (upper left) core. The upper left sample (which measures about $4.2 \mathrm{~mm}$ in diameter) is the other side of the slab shown in figure 3 ; note the size difference in the centers on the two sides.

parent yellow (figure 12c), or an opaque black core (figure 12d). A few had large cores (figure 12b, d). Occasionally, the arms widened toward the edges of the crystals, often with evidence of weathering (figure 12d-f).

With higher magnification, using crossed polarizers, we resolved the striations as thin tubes (figure 13a) that were often filled with birefringent minerals. The arms of the six-rayed stars were formed by massive concentrations of such tubes, which were filled with birefringent minerals (figure 13b), a liquid, or a liquid and gas (figure 13c).

Examination of sections parallel to the c-axis revealed that the tube-like structures are not oriented exactly parallel to the basal plane of the corundum crystals, but rather show a slight inclination, about $5^{\circ}$ (figure 14). This indicates that they are oriented perpendicular to the dominant dipyramidal faces $\omega$, which are inclined about $5^{\circ}$ to the c-axis.

In the black or yellow cores of some of the polished sections, we observed small birefringent mineral inclusions in the form of tiny round spots (figure 13a). These probably represent cross-sections of tubes oriented perpendicular to the basal pinacoid, which means that the tube-like structures also run parallel to the c-axis in the cores of some samples.

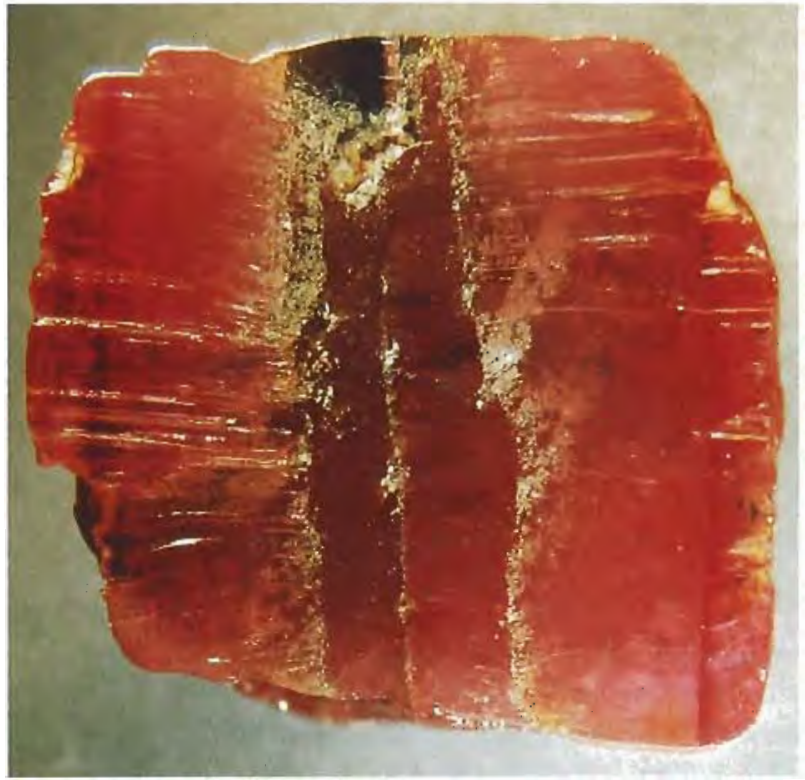

Figure 6. This view, parallel to the c-axis of this 7.2-mm-diameter sample, illustrates the tapered core, which is mostly red but black at one end. Note the strong striations in the outer zones, away from the core.

\section{IDENTIFICATION OF THE MINERAL INCLUSIONS}

The birefringent mineral inclusions in the tubelike structures were analyzed independently by Raman spectroscopy and an electron microprobe. Two types of Raman spectra were found repeatedly in all of the polished slabs (figure 15). These spectra were consistent with calcite and dolomite, as determined by data in the literature (White, 1974; Pinet et al., 1992) and our own reference spectra.

Electron microprobe analysis of the solids filling the tubes confirmed these results and provided some

Figure 7. The arms in this $4 \times 6 \mathrm{~mm}$ trapiche ruby slab "feather out" and widen toward the outer edge of the crystal, almost completely absorbing one of the ruby sectors.

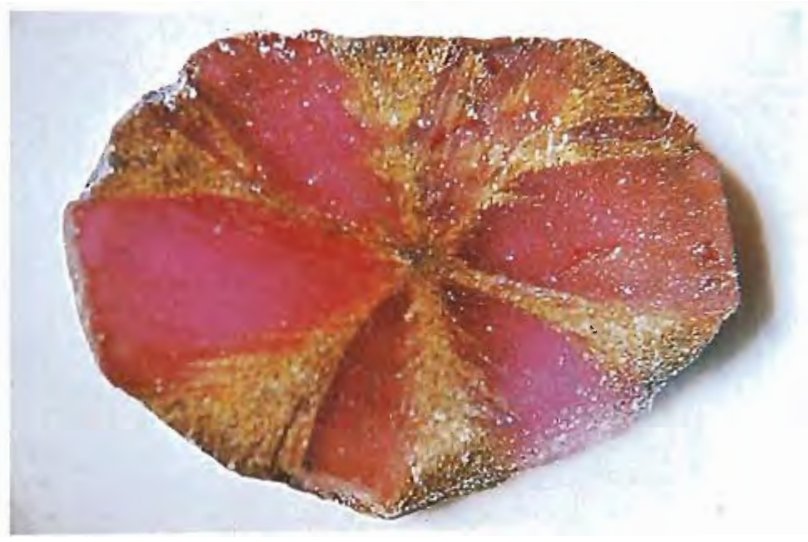




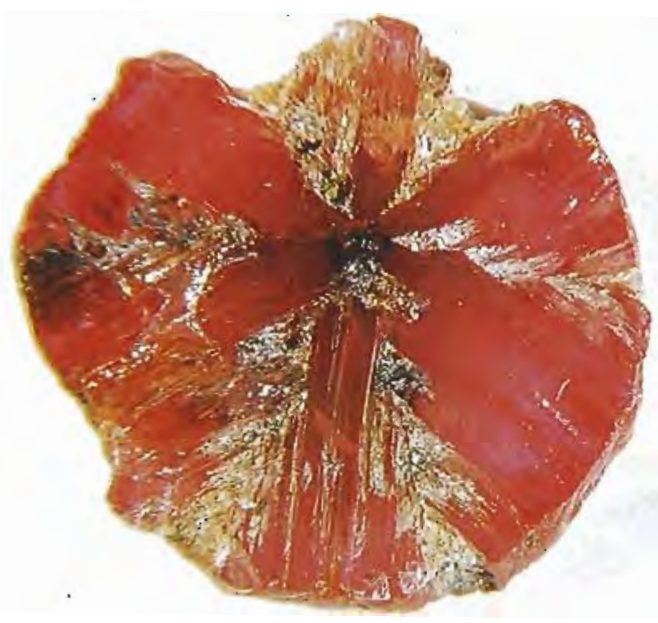

Figure 8. In some of the trapiche rubies in which the arms form triangular zones at the rim of the crystal, weathering has created re-entrant angles. This sample is approximately $7 \times 8 \mathrm{~mm}$.

additional chemical data. Two mineral phases were present in all of the samples examined (figure 16): a magnesium-bearing calcium-rich mineral (calcite) and a carbonate with higher magnesium and lower calcium contents (dolomite). Quantitative chemical analyses gave a $\mathrm{Mg}$ :Ca ratio of 7:93 for the magnesiumbearing calcite (average of five analyses) and a $\mathrm{Mg}: \mathrm{Ca}$ ratio of 49:51 for the dolomite (average of six analyses). No iron was detected in either of these minerals.

Figure 9. When the slabs are examined with transmitted light, the cores and arms of the trapiche rubies appear opaque. The paralle1 striations illustrated in figure 2 are clearly seen in this 3.5-mm-diameter cross-section. Immersion, crossed polarizers.

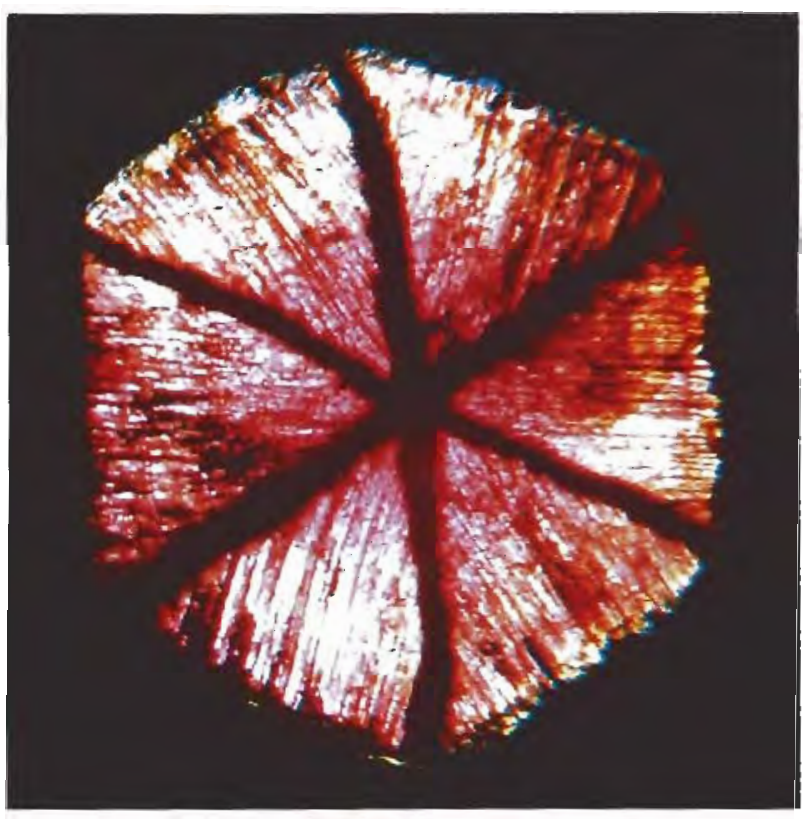

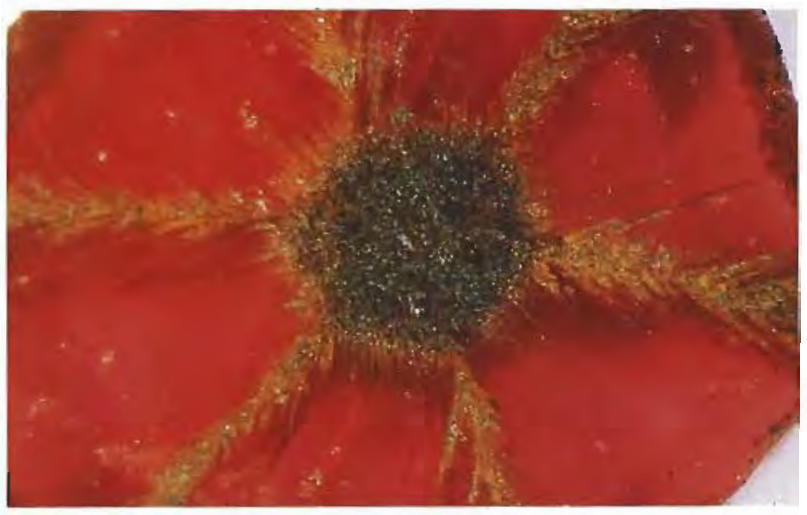

Figure 10. In reflected light, this trapiche ruby slab reveals a series of parallel tube-like structures extending outward from each of the six arms of the star and from the dividing planes between the black core and the six trapezoidal red zones. Magnified 10x.

Because the tube-like structures that extended into the gem "quality ruby sectors were colorless, and the calcite and dolomite inclusions were ironfree, we concluded that the yellow color of the arms and some cores must be due to intense weathering and secondary iron staining of the cavities and tubes. This interpretation was supported by the presence of white arms in some (not deeply weathered) samples and by X-ray fluorescence analyses. In two samples for which we recorded distinct differences, the iron signal in the XRF spectrum of the yellow arm was about four to five times stronger than the iron signal of the adjacent ruby sector (which contained fewer tube-like inclusions).

The massive, nontransparent, yellow triangular areas that broadened toward the outer rim in some samples consist of non-gem-quality corundum, according to $\mathrm{X}$-ray powder diffraction and micro-

Figure 11. In those samples with transparent raby sectors, most of the tube-like inclusions ended close to the arms or dividing planes with the core.

Magnified 50x.

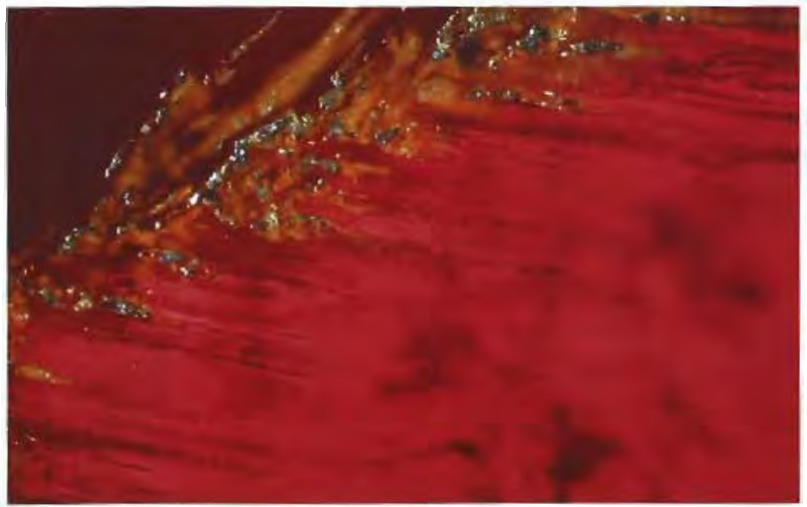



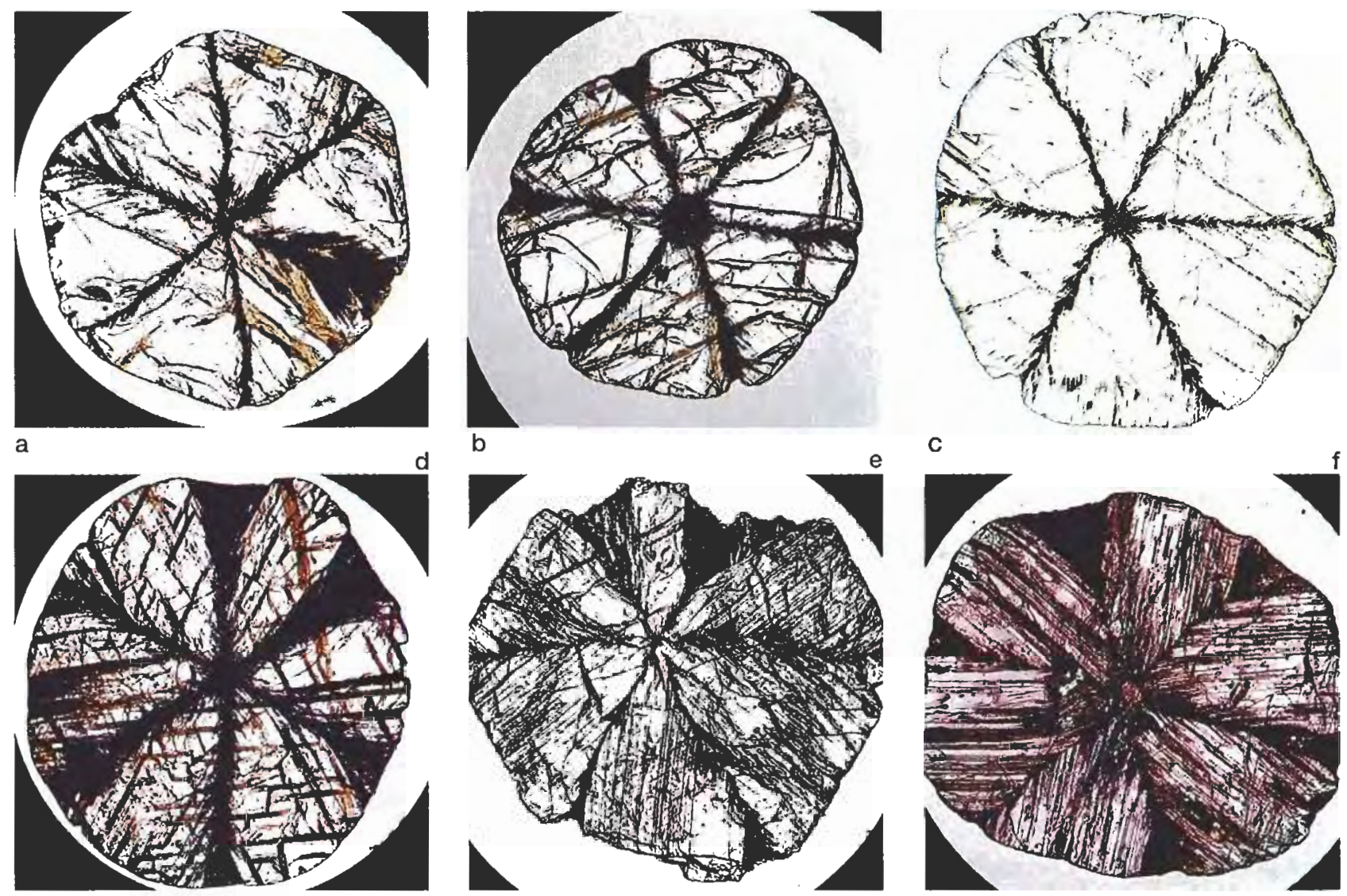
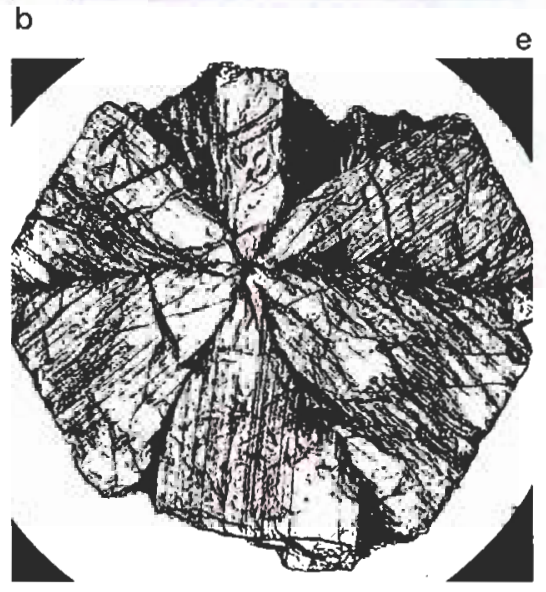

C

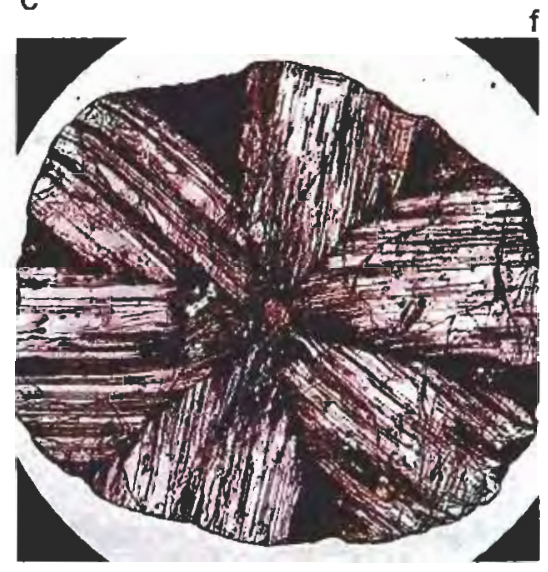

Figure 12. When viewed with transmitted light, the polished basal sections of the trapiche rubies clearly illustrate the different types of star-like structures: (a) the arms of the star in this 3-mm-diameter sample intersect in a small central point; (b) the arms in this 4-mm-diameter section extend outward from the corners of a yellow central core; (c) the arms in this 4.2-mm-diameter section extend outward from the corners of a small yellow central core, with evidence of weathering in the arms at the rim (re-entrant angles); (d) the arms in this 3.2-mm-diameter section, which extend from a black core, get thicker as they approach the outer rim of the crystal, with evidence of weathering at the rim; (e) weathering is more extensive in the arms of this 5-mm-diameter sample, which intersect in a small central point; and (f) the arms in this $4.5 \times 5 \mathrm{~mm}$ sample extend outward from a red core, ending in partially weathered triangular structures at the rim of the crystal. Note the profusion of tube-like inclusions in the ruby sectors of semi-transparent samples e-f, as compared to the ruby sectors of transparent samples $a-c$. Polished sections $a, b$, and $d-f$ are $200 \mu \mathrm{m}$ thick; sample $c$ is $20 \mu \mathrm{m}$ thick. Photomicrographs by O. Medenbach.

probe analyses. In the samples we examined, these sectors contained a massive concentration of inclusions, apparently also accompanied by intense weathering and iron staining.

\section{DISCUSSION}

Nomenclature. These ruby samples share a number of common structural features with trapiche emeralds from Colombia, as described in the mineralogic and gemological literature (Bernauer, 1926; McKague, 1964; Schiffmann, 1968; Nassau and Jackson, 1970; O’Donoghue, 1971). In both mineral species, corundum and beryl, hexagonal single crystals are divided by included material into six distinct triangular or trapezoidal growth sectors, depending on the presence or absence of a central core. The arms of the six-rayed stars consist of the host (ruby or emerald| with inclusions of other minerals: calcite and dolomite for ruby, albite for emerald. In both gem materials, the central core consists of the host mineral alone or of the host mineral plus inclusions (similar to the composition of the arms), and it is typically tapered.

Oriented striations (tube-like inclusions) occur both at the outline of the core and extending outward from the nontransparent arms into the transparent ruby or emerald sectors. In our ruby samples, these striations were oriented perpendicular to the dominant crystal form, that is, perpendicular to the hexagonal dipyramid $\omega\{1414 \overline{28} 3\}$; in emerald, they are perpendicular to the first-order hexagonal prism $m\{10 \overline{1} 0\}$.

In general, most of the structural characteristics that have been described for various trapiche emer- 

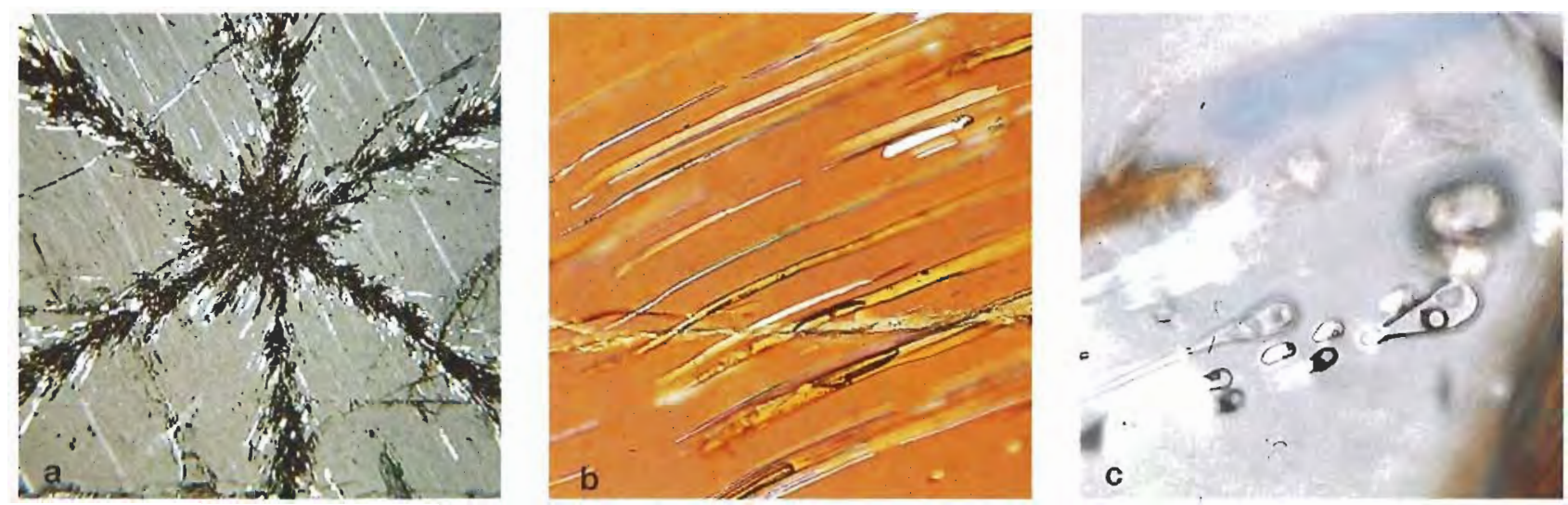

Figure 13. When the polished sections were viewed with higher magnification and crossed polarizers, it became evident that the tube-like structures (a) were filled with birefringent minerals (b), or with a liquid or liquid and gas (c). The tiny round spots in the core of figure a are actually cross-sections of tubes that run perpendicular to the basal pinacoid. Photomicrographs by O. Medenbach; $a=$ magnified 10x, $b=40 x, c=40 x$.

alds from Colombia (see, e.g., Bemauer, 1926; Nassau and Jackson, 1970) were also found in the sectored rubies described in this article. Thus, it seems reasonable to apply the term trapiche not only to sectored emeralds from Colombia, but also to similarly sectored rubies regardless of geographic origin.

Formation Sequence. Discussions as to whether the structural features observed in Colombian trapiche emeralds are primary or secondary in origin (i.e., whether they formed during or after the formation of the host emerald) are ongoing (McKague, 1964; Nassau and Jackson, 1970; Petreus, 1974). However, the arrangement of the tube-like inclusions in our samples suggests that the sectored structure of the trapiche rubies described in this article is primary. Specifically, we believe that the red or black core formed first; then, a change in the growth environ-

Figure 14. In this view of a 5.9-mm-diameter trapiche ruby crystal parallel to the c-axis, the tube-like inclusions show a small inclination to the basal plane.

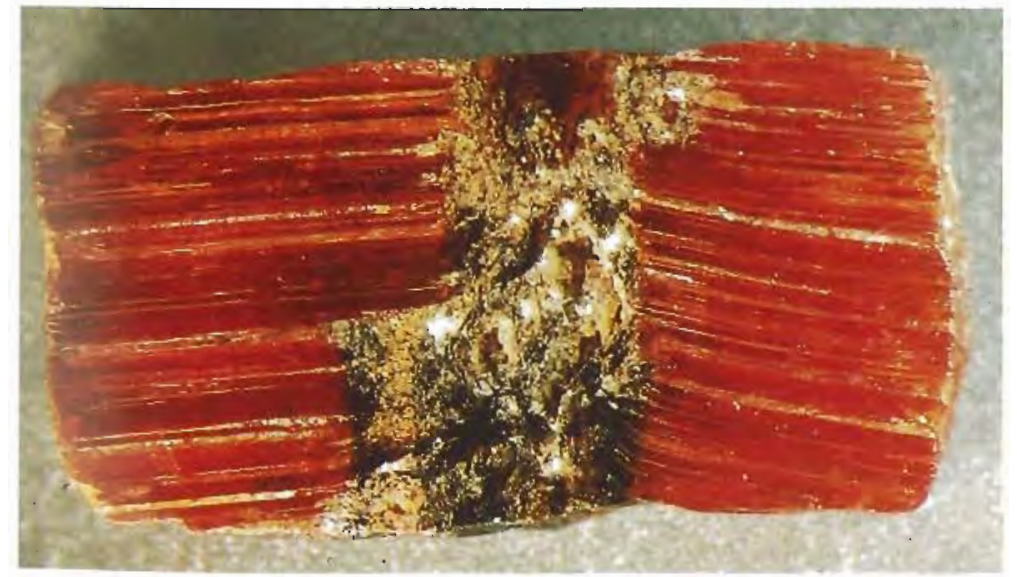

ment caused the massive formation of tube-like inclusions at the outer edge of the core. Subsequent to this event, new tube-like inclusions formed at the boundaries between the six dipyramidal growth sectors. In the direction along the c-axis, tube-like inclu-

Figure 15. On the basis of these Raman spectra (note that scales are different), the mineral inclusions in the tube-like structures were identified as $(A)$ calcite and $(B)$ dolomite. The lines at 414.8 and $749.7 \mathrm{~cm}^{-1}$ (not labeled) are assigned to the conundum host.

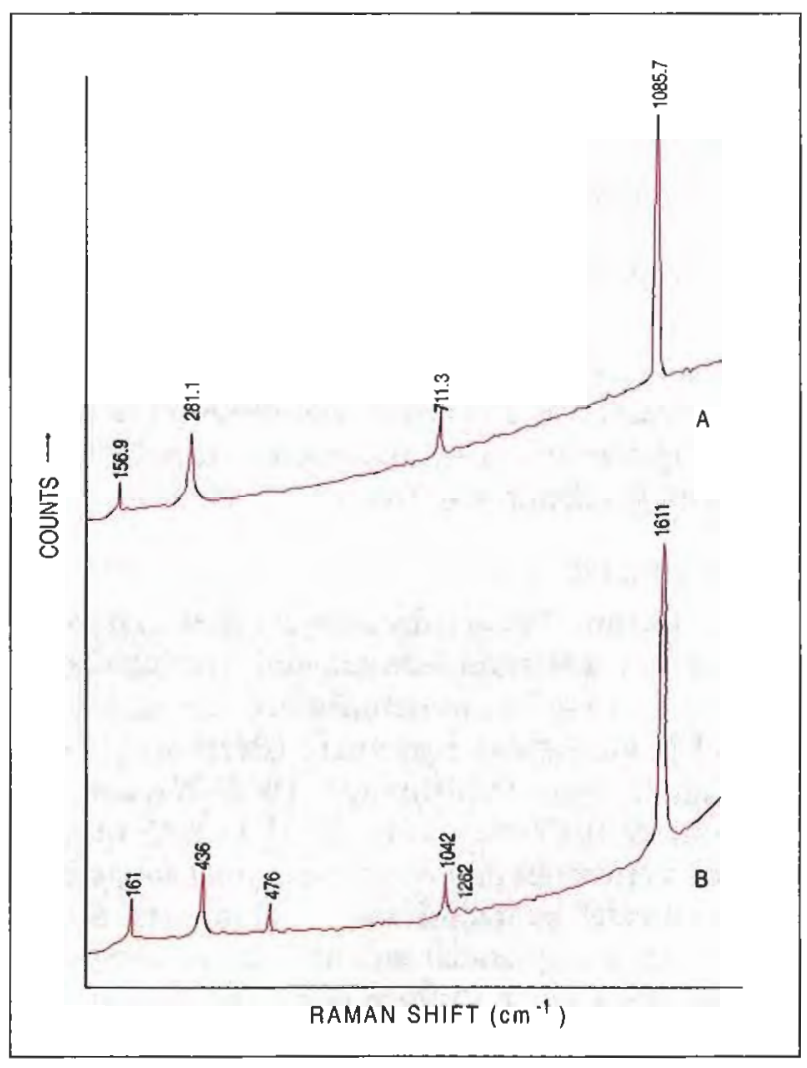




\section{BOX A: TRAPICHE SAPPHIRE}

A different type of trapiche emerald, which originated from the state of Goiás, Brazil, was described by DelRe (1994). The samples he examined consisted of a hexagonal central core with dark, trapezoidal, nontransparent areas extending inward from the six prism faces of the crystal; the trapezoidal areas were separated by narrower green transparent zones that extended from the corners of the central core. Consequently, the Brazilian material appeared to be a photographic "negative" of Colombian trapiche emeralds.

Recently, trapiche corundum with a similar "negative" appearance was seen in the gem market. Ten sapphires with a sectored structure were offered at the 1996 Basel fair by a Berlin gem dealer. He had purchased several cabochons and one faceted trapiche sapphire in Myanmar in early 1996; at that time, he was told that the samples originated from the Mong Hsu mining area (H.-J. Engelbrecht, pers. comm., 1996).

A 6.59 ct trapiche sapphire was purchased by one of the authors (HAH). It is whitish gray in color, with six almost triangular white reflective (opaque) areas. Small bands of a darker gray, less translucent material delineate the six triangular zones. The overall effect is of a fixed six-rayed hexagonal star (figure A-1). The white reflective material in the triangular areas close-

Figure A-1. Whitish gray sapphires with a sectored structure have also appeared recently in the gem market. A 6.59 ct trapiche sapphire is shown here with the 1.55 ct trapiche ruby cabochon for comparison.

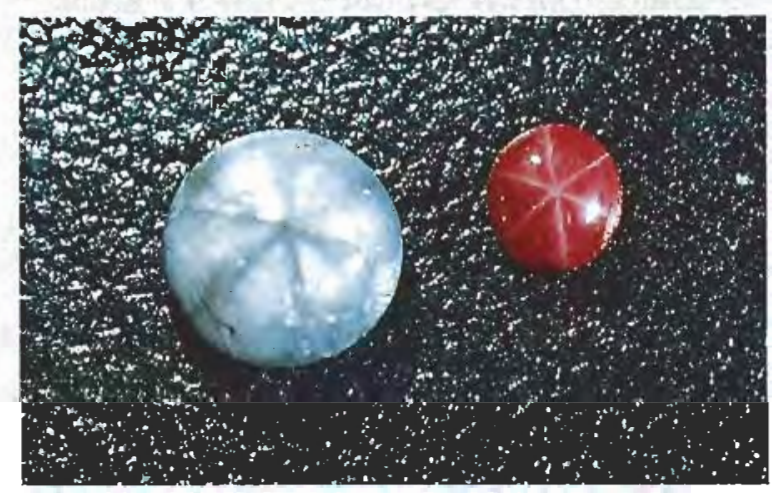

ly resembles "silk," and microscopic examination confirmed the presence in these areas of a dense pattem of rutile needles, similar to that which is commonly seen in Burmese rubies and sapphires. In addition, hexagonal growth zoning parallel to prism and/or dipyramidal faces established that the six rays of the star in this sample are oriented perpendicular to the prism and/or dipyramidal faces of the corundum crystal (figure A-2). This indicates that the six arms of the star in this trapiche sapphire are oriented perpendicular to the arms of the stars in the trapiche rubies described in this article.

Microscopic examination also revealed yellowappearing mineral inclusions that were concentrated in the areas confined by the six arms of the star. After carefully repolishing the back of the sapphire cabochon, we were able to identify these inclusions by SEM-EDS as phlogopite. These phlogopite inclusions, which were undoubtedly concentrated during crystal growth, are responsible for the dark gray appearance of the arms of the star.

Figure A-2. These schematic drawings illustrate differences between the trapiche rubies and trapiche sapphire studied. In the nuby (a), the dividing planes between the red sectors are formed by tube-like inclusions oriented perpendicular to dipyramidal crystal faces (see figure 12). In the sapphire (b), the dividing planes are formed by zones with a high concentration of phlogopite inclusions perpendicular to prismatic or dipyramidal growth planes (broken lines); the rutile needles in the whitish reflecting growth zones are oriented parallel to the growth planes, as indicated here by the arms of the small six-rayed stars.

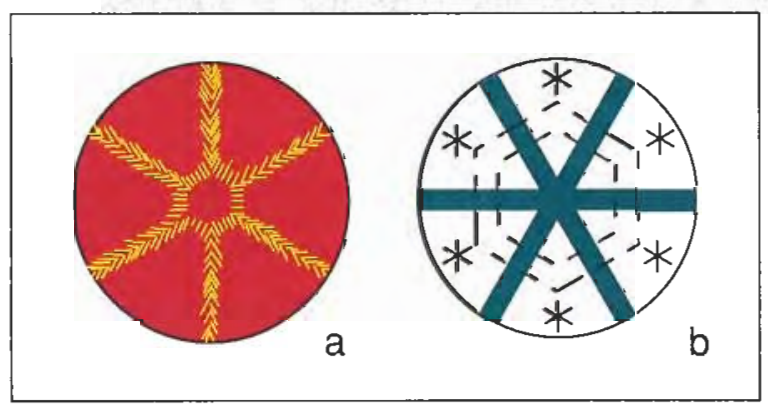

sions also formed in basal growth sectors, with an orientation perpendicular to the basal pinacoid. Where the basal faces were prominent, discrete cores with calcite and dolomite inclusions in tube-like structures formed; where the basal faces were small or absent, smaller cores or intersection points between the arms of the stars formed.
The appearance of the samples described in this article can be explained in terms of their relative position in this trapiche ruby growth sequence: Samples with red and/or black cores on either end of the crystal fragments were grown at an earlier stage, and those with yellow cores or intersection points were grown in a later stage. 

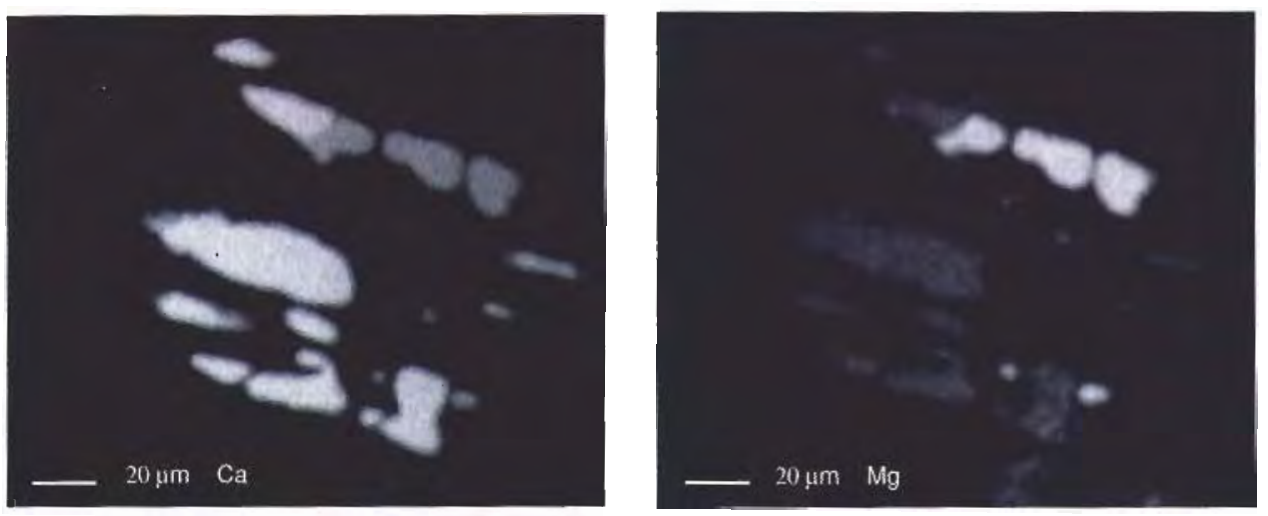

Figure 16. Electron microprobe-generated $X$-ray scanning images for $\mathrm{Ca}$ (left) and $\mathrm{Mg}$ (right) confirmed the presence of calcite and dolomite in the tube-like inclusions. The more intense calcite image reflects the higher calcium content in this mineral.

Origin. As mentioned previously, some of the material described in this article was selected by the authors from large parcels of reportedly Mong Hsu rough in Mae Sai, northern Thailand. Certain characteristics of these trapiche rubies are closely related to those of untreated rubies from Mong Hsu (see Peretti et al., 1995): The dominant crystal form is the hexagonal dipyramid $\omega\{1414 \overline{28} 3\}$, typical samples reveal dark violet to almost black central cores and red rims, and an abrupt change of growth conditions is evident in the growth sequence. Furthermore, calcite and dolomite are components of the Mong Hsu host rock; Peretti et al. (1996) described a ruby crystal from Mong Hsu in a calcite vein, embedded in a dolomite marble.

However, there are also some indications that Vietnam might be the country of origin for all or some of the samples. One Bangkok gem dealer mentioned that he had seen rubies of this type coming from Vietnam (K. Siu, pers. comm., 1995). In addition, rubies with sectored growth structures were seen about five years ago in large parcels of material from Vietnam, which probably originated from the Luc Yen mining area (C. P. Smith, pers. comm., 1996), and a purple-pink trapiche sapphire described by Koivula et al. (1994) reportedly came from a parcel of Vietnamese rough.

\section{CONCLUSION}

Trapiche rubies represent a new variety of corundum that is similar in appearance to trapiche emeralds. Like trapiche emeralds, these rubies are composed of six triangular or trapezoidal sectors formed by the fixed arms of a six-rayed star, with or without a tapered core. The arms consist of the host material and massive concentrations of inclusions. In trapiche rubies, these inclusions are tube-like structures that are oriented perpendicular to dominant dipyramidal crystal faces. The minerals in these tubes are calcite and dolomite. Although the arrangement of these inclusions suggests that the star pattern formed at the same time as the ruby crystal formed, the detailed growth mechanism of the trapiche ruby pattern cannot be explained at present.

\section{REFERENCES}

Bernauer F. (1926) Die sog. Smaragddrillinge von Muzo und ihre optischen Anomalien. Neues Jahrbuch für Mineralogie, Geologie und Paläontologie, Supplemental Vol. 54, Part A, pp. $205-242$.

DelRe N. (1994) Gem trade lab notes: Emerald, trapiche from a new locality. Gems ev Gemology, Vol. 30, No. 2, pp. 116-117

Hänni H.A., Kiefert L., Chalain J.-P., Wilcock I.C. (1996) Ein Renishaw Raman Mikroskop im gemmologischen Labor: Erste Erfahrungen bei der Anwendung [A Renishaw Raman Microscope in the gemmological laboratory: First application experiences]. Gemmologie. Zeitschrift der Deutschen Gemmologischen Gesellschaft, Vol. 45, No. 2, 1996, pp. $55-70$.

Henn U., Bank H. (1996) Trapicheartige Konunde aus Myanmar. Gemmologie. Zeitschrift der Deutschen Gemmologischen Gesellschaft, Vol. 45, No. 1, pp. 23-24.

Koivula J.I., Kammerling R.C., Fritsch E. (1994) Gem news: "Trapiche" purple-pink sapphire. Gems et) Gemology, Vol. 30, No. 3, p. 197.

McKague H.L. (1964) Trapiche emeralds from Colombia, part I Gems \&) Gemology, Vol. 11, No. 7, pp. 210-213, 223.

Müllenmeister H.-J., Zang J. (1995) Ein Trapiche-Rubin aus Myanmar (Burma). Lapis, Vol. 20, No. 12, p. 50.
Nassau K., Jackson K.A. (1970) Trapiche emeralds from Chivor and Muzo, Colombia. American Mineralogist, Vol. 55, No. 3/4, pp. 416-427.

ODonoghue M.J. (1971) Trapiche emerald. Journal of Gemmology, Vol. 12, No 8, pp. 329-332.

Peretti A., Mullis I., Mouawad F. (1996) The role of fluorine in the formation of colour-zoning in rubies from Mong Hsu, Myanmar (Burma). Journal of Gemmology, Vol. 25, No. 1, pp. 3-19.

Peretti A., Schmetzer K., Bernhardt H.-J., Mouawad F. (1995) Rubies from Mong Hsu. Gems \&) Gemmology, Vol. 31, No. 1, pp. $2-26$.

Petreus I. (1974) The divided structure of crystals, I: Secondary structures and habits. Neues Jahrbuch für Mineralogie Abhandlungen, Vol. 122, No. 3, pp. 314-338

Pinct M., Smith D.C., Lasnier B. (1992) Utilité de la microsonde Raman pour l'identification non-destructive des gemmes. In La Microsonde Raman en Gemmologie, Association Françaisc de Gemmologie, Paris, pp. 11-60.

Schiffmann C.A. (1968) Unusual emeralds. Journal of Gemmology, Vol. 11, No. 4, pp. 105-114.

White W.B. (1974) The carbonate minerals. In V.C. Farmer, Ed., The Infrared Spectra of Minerals, Mineralogical Society Monograph 4, London, pp. 227-284. 